\title{
A Comprehensive Method for Optimum Sizing of Hybrid Energy Systems using Intelligence Evolutionary Algorithms
}

\author{
Ahmad Rouhani ${ }^{1 *}$, Hossein Kord ${ }^{2}$ and Mahdi Mehrabi ${ }^{3}$ \\ YYoung Researchers and Elite Club, Shiraz Branch, Islamic Azad University, Shiraz, Iran; rouhani@biau.ac.ir \\ ${ }^{2}$ Young Researchers and Elite Club, Beyza Branch, Islamic Azad University, Beyza, Iran; hkord63@yahoo.com \\ 3Islamic Azad University, Shiraz Branch, Shiraz, Iran; mehrabi@iaushiraz.net
}

\begin{abstract}
Exhibition a comprehensive method for optimum sizing of hybrid energy systems using intelligence evolutionary algorithms is performed in this paper. The aim of the method is to find the optimum sizes of the hybrid energy systems among the numerous configurations to reach the expected reliability and the lowest LCE. In this respect, the mathematical model of each component is represented and the components are simulated by means of a comprehensive energy management strategy. Ability to comprise reliability constraints is another outstanding trait of this model. After formulation of the cost function consists of investment and operation cost of proposed hybrid system including reliability constraints, GA and PSO are applied to optimize the cost function. This model can be implemented to such hybrid energy systems with other configurations too. Proficiency of the presented model is shown by means of the results of the simulations implemented via actual weather details from Shiraz weather data.
\end{abstract}

Keywords: Evolutionary Algorithms, Hybrid Energy System, Optimization, Power Management, Reliability.

\section{Introduction}

Dramatic increase in energy consumption, environmental concerns, reducingfossilfuelresourcesand theirhigh costare major factors in the development of renewable energies [1]. The aforementioned limitations, have led the research community to seek for alternative Renewable Energy Sources (RES). Among the renewable energy, wind and sun are most important. On the other hand, special emphasis has been given on the development and implementation of fuel cell (FC) systems, for both academic purposes and industrial applications [2]. Fuel cells may be considered as continuous chemical reactors which convert fuel and oxidant chemical potential into electrical energy. The key advantages of fuel cells compared to the conventional electrical power generation technologies are: higher efficiency, especially when the waste heat is used for co-generation, quiet operation suitable for residential applications, and almost zero levels of produced pollutant gases. The most important drawback concerning fuel cell technology is that the basic fuel they use (hydrogen) does not exist free in nature [2].

The major application of a stand-alone power system is in remote areas where utility lines are uneconomical to install due to terrain, the right-of-way difficulties or the environmental concerns. According to the World Bank, more than 2 billion people live in villages that are not yet connected to utility lines [3]. These villages are the largest potential market of the hybrid stand-alone systems. Many alternative energy sources including wind, photovoltaic (PV), FC, diesel system, gas turbine, and micro turbine can be used to build a hybrid energy system [4-11]. 
In previous studies, the optimal sizing problem is solved for wind-fuel cell hybrid system [9], and for windsolar-fuel cell hybrid system [10]. Furthermore the optimal sizing of wind-solar-battery hybrid system is performed by means of genetic algorithm [11].

In this paper, a stand-alone hybrid alternative energy system consisting of wind generator (WG), PV, FC, electrolyser, and battery is proposed for stand-alone applications. WG and PV are the primary power source of the system, and the FC-electrolyser combination is used as a backup and a long-term storage system. A battery bank is also used in the system for short-time backup to supply transient power. The details of the major system components, system reliability and economical model are also discussed in the paper.

An overall power management strategy is designed for the system to coordinate the power flows among the different energy sources. Simulation studies have been carried out to verify the system performance using practical load profile and real weather data form Shiraz area in south-west Iran. It is to mention that there are many similar regions around the world with this typical situation that can be expanded.

The paper is organized as follows: Firstly, the mathematical model of hybrid WG/PV/FC system is developed. Secondly, an overall control strategy for power management among different energy is designed. The system reliability model, which is based on loss of power supply probability (LPSP) technique, and the system economical model, based on the levelized cost of energy (LCE) concept are presented in Section 4 and 5. Section 6 describes the optimization methods. Lastly, the simulation results and conclusion are presented.

\section{Modeling of the Hybrid WG/PV/ FC System Components}

As shown in Figure 1 this paper develops the hybrid system consisting of proton exchange membrane (PEM) FC, WG and PV modules that uses battery to store the energy and electrolyser to produce hydrogen (H2). The hydrogen can be produced, during the surplus of energy production, from water by electrolysis and stored in a container for further use. Indeed the electrolyser in this model is used as a dump load.

\subsection{WG Model}

A wind turbine converts the kinetic energy of wind into mechanical energy. Wind generators can be separated according to the

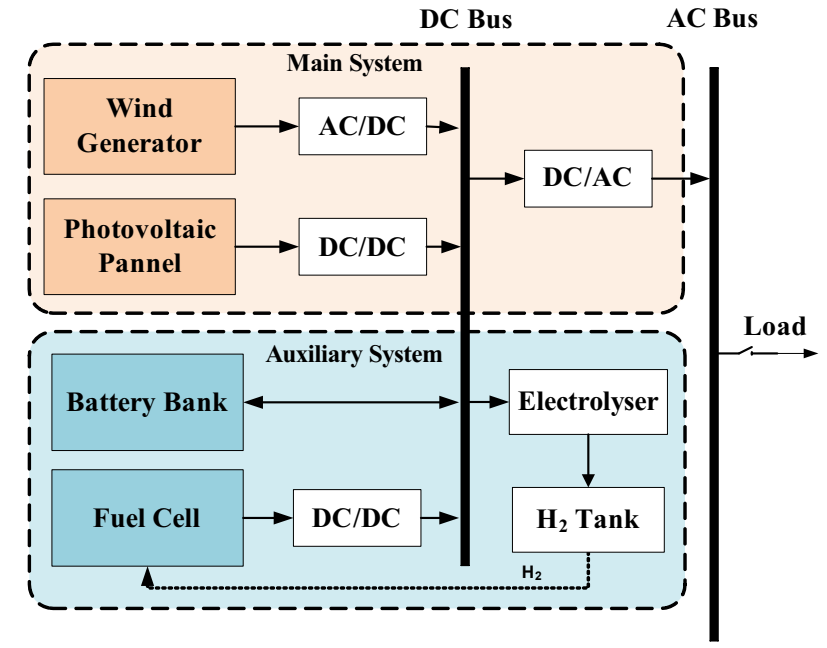

Figure 1. Wind Generator/Photovoltaic/Battery/Fuel cell hybrid energy system.

type of the axis about which the turbine rotates. Turbines that rotate around a horizontal axis are more commonly used than those that rotate around a vertical axis. The model is based on the characteristics of the power of turbine at steady state. The fitting equation of the output characteristics of wind generator can be expressed as [3].

$$
P_{W G}= \begin{cases}0 & V<V_{c i} \\ a V^{3}-b P_{r} & V_{c i}<V<V_{r} \\ P_{r} & V_{r}<V<V_{c o} \\ 0 & V>V_{c o}\end{cases}
$$

where $P_{W G}$ is the output power of wind generator at wind speed $V, P_{r}$ is the rated power, $V$ is the wind speed at the hub height, $V_{c i}, V_{r}$ and $V_{c o}$ are the cut-in, rated and cut-out wind speeds, respectively.

$a$ and $b$ are the polynomial coefficients of the cubic spine interpolation functions which depend on the wind turbine generator type, as shown in the equation below:

$$
a=\frac{P_{r}}{V_{r}^{3}-V_{c i}^{3}} \quad b=\frac{V_{c i}^{3}}{V_{r}^{3}-V_{c i}{ }^{3}}
$$

\subsection{PV Model}

As the operation and the performance of a PV generator is interested in its maximum power, the models describing the PV module's maximum power output behaviours are more practical for PV system assessment. In this paper, a mathematical model for estimating the power output of PV modules is used. The estimation is carried out using a computer program, which uses a subroutine for determining 
the power output of a PV module. Using the solar radiation available on the tilted surface, the ambient temperature and the manufacturer's data for the PV modules as model inputs, the power output of the PV generator $\left(P_{P V}\right)$ can be calculated according to the following equation [12]:

$$
P_{P V}=\eta_{g} N A_{m} G_{t}
$$

where $\eta_{g}$ is the instantaneous PV generator efficiency, $A_{m}$ the area of a single module used in a system $\left(\mathrm{m}^{2}\right), G_{t}$ the global irradiance incident on the titled plane $\left(\mathrm{W} / \mathrm{m}^{2}\right)$ and $N$ is the number of modules used in system. All the energy losses in a PV generator, including connection losses, wiring losses and other losses, are assumed to be zero. The instantaneous photovoltaic generator efficiency is represented by the following equation [13].

$$
\eta_{g}=\eta_{r} \eta_{p t}\left[1-\beta_{t}\left(T_{c}-T_{r}\right)\right]
$$

where $\eta_{r}$ is the PV generator reference efficiency, $\eta_{p t}$ the efficiency of power tracking equipment, which is equal to 1 if a perfect maximum power point tracker is used, $T_{c}$ the temperature of $\mathrm{PV}$ cell $\left({ }^{\circ} \mathrm{C}\right), T_{r}$ the $\mathrm{PV}$ cell reference temperature and $\beta_{t}$ is the temperature coefficient of efficiency, ranging from 0.004 to 0.006 ( per $^{\circ} \mathrm{C}$ ).

Based on the energy balance proposed by [14], the PV cell temperature can be expressed as follows:

$$
T_{c}=T_{a}+G_{t}\left(\frac{\tau \alpha}{U_{L}}\right)
$$

where $T_{a}$ is the ambient temperature $\left({ }^{\circ} \mathrm{C}\right), U_{L}$ is the overall heat loss coefficient $\left(\mathrm{W} / \mathrm{m}^{2}\right.$ per $\left.{ }^{\circ} \mathrm{C}\right), \tau$ and $\alpha$ represent, respectively, the transmittance and absorptance coefficients of PV cells. The overall heat loss coefficient $\left(\tau \alpha / U_{L}\right)$ can be estimated from the nominal operating cell temperature (NOCT) as follows [15]:

$$
\left(\frac{\tau \alpha}{U_{L}}\right)=\frac{N O C T-20}{800}
$$

Consequently, the instantaneous PV generator efficiency can be expressed as follows:

$$
\eta_{g}=\eta_{r} \eta_{p t} \times\left\{\begin{array}{l}
1-\beta_{t}\left(T_{a}-T_{c}\right)-\beta_{t} G_{t}\left(\frac{N O C T-20}{800}\right) \\
\left(1-\eta_{r} \eta_{p t}\right)
\end{array}\right\}
$$

where $\eta_{p t} \beta_{t}$, NOCT, $A_{m}$ are parameters that depend on the type of module, and given by the manufacturer of the modules. Note that 800 in $(5)$ is in $\left(\mathrm{W} / \mathrm{m}^{2}\right)$, and NOCT $\left({ }^{\circ} \mathrm{C}\right)$ ranges from 40 to $70\left({ }^{\circ} \mathrm{C}\right)[16]$.

\subsection{Electrolyser Model}

The electrolyser is simply considered as a constant gain corresponding to the electrolyser efficiency $\left(\eta_{\text {ELEC }}\right)$ and an integrator to determine the amount of produced hydrogen. The amount of hydrogen consumed by the FC is also determined. The difference between both gives the amount of available stored hydrogen, following (8).

$$
S O C_{E L E C}=\int\left(P_{E L E C} \times \eta_{E L E C}\right) d t-\int \frac{P_{F C}}{\eta_{F C}}
$$

where $S O C_{E L E C}$ is the state of charge electrolyser, $P_{E L E C}$ is electrolyser power, $P_{F C}$ is $F C$ power and $\eta_{F C}$ is the efficiency of FC stack.

\subsection{FC Model}

The FC supplies the system during critical periods when solar insulation is very weak and the lamp consumption is very high (winter season). The PEMFC is particularly well suitable for this work. It produces electricity from the hydrogen without any greenhouse emission, if hydrogen comes from a clean source like an electrolysis process associated with renewable energy. PEM fuel cell has reliable performance under intermittent supply and is commercially available at large industrial scale capacities. This kind of fuel cell is suitable for large-scale stationary generation and has fast dynamic response with a power release response time of only 1 to 3 seconds [17].This model permits to calculate hydrogen consumption according to the delivered power. It should be noticed that the FC auxiliary system needs around $20 \%$ of the FC net power (for cooling and air pressurization) [18].

\subsection{Battery Model}

The battery input power $\left(P_{B A T}\right)$ can be positive or negative depending on the charge or discharge mode of operation. The battery power is obtained from (9).

$$
P_{B A T}=P_{W G}+P_{P V}+P_{F C}-P_{L O A D}
$$

The state of charge $\left(S O C_{B A T}\right)$ is deduced from the battery power and efficiency $[18,19]$ :

$$
S O C_{B A T}=\int\left(P_{B A T, \text { charging }} \times \eta_{B A T}-P_{B A T, \text { decharging }}\right) d t
$$

The FC is activated when the battery SOC is lower than a threshold value. On the contrary, FC is stopped and the electrolyser starts up when SOC is higher to a threshold value. The battery power given in (9) becomes the electrolyser power following (11). 


$$
P_{E L E C}=P_{W G}+P_{P V}-P_{L O A D}
$$

At any hour, the storage capacity $\left(C_{B A T}(t)\right)$ is subject to the following constraints:

$$
C_{B A T, \min } \leq C_{B A T}(t) \leq C_{B A T, \max }
$$

where $C_{B A T \text {, max }}$ and $C_{B A T \text {, min }}$ are the maximum and minimum allowable storage capacity, respectively.

\section{Power Management Strategy}

An overall control strategy for power management among different energy sources in a multi-source energy system is needed. Figure 2 shows the block diagram of the overall control strategy for the proposed hybrid alternative energy system. The power difference between the generation sources and the load demand is calculated as:

$$
P_{N e t}=P_{W G}+P_{P V}-P_{L O A D}-P_{S C}
$$

where, $P_{S C}$ is the self-consumed power for the system operation. The governing control strategy is that, at any time, any excess WG and PV generated power $\left(P_{\text {Net }}>0\right)$ is supplied to the battery or the electrolyser to generate $\mathrm{H}_{2}$ that is delivered to the hydrogen storage tanks through a gas compressor. Therefore the power balance equation given in (13) can be written as:

$$
\begin{gathered}
P_{W G}+P_{P V}=P_{L O A D}+P_{B A T, \text { Charging }}+P_{S C},\left(S O C<S O C_{M A X}\right) \\
P_{W G}+P_{P V}=P_{L O A D}+P_{E L E C}+P_{S C},\left(S O C=S O C_{M A X}\right)
\end{gathered}
$$

When there is a defect in power generation $\left(P_{N E T}<0\right)$, the battery and/or the FC stack begins to produce energy for the load. Therefore, the power balance equation for this situation can be written as:

$$
\begin{gathered}
\left.P_{W G}+P_{P V}+P_{B A T, D i s c h a r g i n g}=P_{L O A D}+P_{S C},(S O C\rangle S O C_{M I N}\right) \\
P_{W G}+P_{P V}+P_{F C}+\left(P_{B A T, D i s c h a r g i n g}\right)=P_{L O A D}+P_{S C},\left(S O C\left\langle S O C_{M I N}\right)\right.
\end{gathered}
$$

\section{Modeling of System Reliability}

Several approaches are used to achieve the optimal configurations of hybrid systems in terms of technical analysis. In this study, the technical sizing model for the HPFS is developed according to the concept of LPSP to evaluate the reliability of hybrid systems [20]. The methodology used can be summarized in the following steps:

The total power $\left(P_{t o t}\right)$, generated by the WG, PV generator and FC at hour $\mathrm{t}$ is calculated as follows:

$$
P_{t o t}(t)=P_{W G}(t)+P_{P V}(t)+P_{F C}(t)
$$

Then, the inverter input power $\left(P_{i n v}(t)\right)$, is calculated using the corresponding load power requirements, as follows:

$$
P_{i n v}(t)=\frac{P_{L O A D}(t)}{\eta_{n v}}
$$

where $P_{L O A D}(t)$ is the power consumed by the load at hour $\mathrm{t}$, $\eta_{\text {inv }}$ is the inverter efficiency (95\% in this study). It should be noticed that the electrolyser power is added to $P_{L O A D}$ when it is activated. Three states may be appearing:

a) The total power generated by the WG, PV and FC is greater than the power needed by the load, $P_{i n v}$. In this case, the energy surplus is stored in the batteries and the new storage capacity is calculated using (10) until the full capacity is obtained. The remainder of the available power is dedicated to the electrolyser to produce hydrogen.

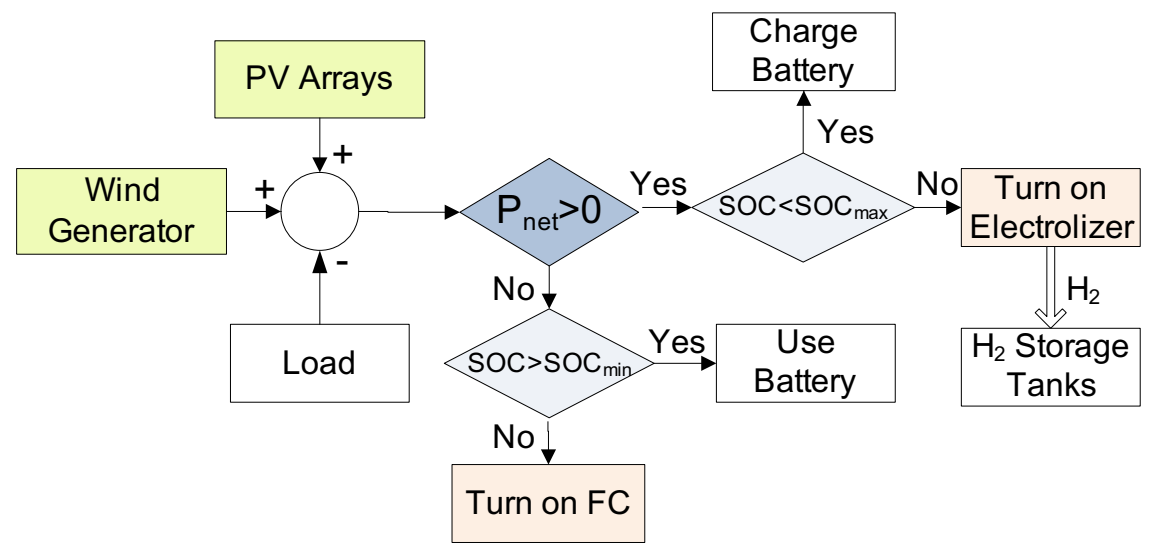

Figure 2. Block diagram of the overall control scheme for the proposed hybrid alternative energy system. 
b) The total WG, PV and FC power is less than the power needed by the load $\left(P_{i n v}\right)$, the energy deficit is covered by the storage and a new battery capacity is calculated using (10).

c) In case of inverter input and total power equality, the storage capacity remains unchanged.

In case (a) when the batteries capacity reaches a maximum value $\left(C_{B A T \text {,max }}\right)$, the control system stops the charging process. The wasted energy, defined as the energy produced and not used by the system, for hour $t$ is calculated as follows:

$$
W E(t)=P_{t o t}(t) \Delta t-\left(\frac{P_{L O A D}(t)}{\eta_{n v}} \Delta t+\left(\frac{C_{B A T, \max }-C_{B A T}(t-1)}{\eta_{\text {hha }}}\right)\right)
$$

In case (b), if the batteries capacity decreases to its minimum level $\left(C_{B A T, \text { min }}\right)$, the control system disconnects the load and the energy deficit, loss of power supply for hour $t$ can be expressed as follows [21]:

$$
L P S(t)=P_{L O A D}(t) \Delta t-\left(\begin{array}{l}
\left(P_{W G}(t)+P_{P V}(t)+P_{F C}(t)\right) \Delta t \\
+C_{B A T}(t-1)-C_{B A T, \text { min }}
\end{array}\right) \eta_{i n v}
$$

where $\Delta t$ is the step of time used for the calculations (in this study $\Delta t=1 \mathrm{~h}$ ). During that time, the power produced by the WG, PV and FC is assumed constant. So, the power is numerically equal to the energy within this time step.

The loss of power supply probability, for a considered period T, can be defined as the ratio of all the LPS $(t)$ values over the total load required during that period. The LPSP technique is considered as technical implemented criteria for sizing a hybrid WG/PV/FC system employing a battery bank and an electrolyser. The technical model for hybrid system sizing is developed according to the LPSP technique [22].

$$
L P S P=\sum_{t=1}^{T} L P S(t) / \sum_{t=1}^{T} P_{L O A D}(t) \Delta t
$$

where $T$ is the operation time (in this study, $T=1$ year). One more concept can be introduced too. The concept is the energy excess percentage, which is defined as the wasted energy divided by the total energy produced by the WG, PV and FC during the considered period.

$$
E X C(t)=\frac{W E(t)}{E_{t o t}(t)}
$$

For a given LPSP value and a defined period, many configurations can technically meet the required reliability demand of power supply. The optimal configuration can be identified finally from these set of configurations by achieving the lowest LCE. This can be performed by applying an economical model developed in Section 4.

\section{Economical Model}

There are different financial analysis models based on "discounted cash flow analysis" such as, net present value, required revenues analysis, profitability index, internal rate of return and levelized cost [16]. These analysis models are termed as financial indicators and are used for comparison of different projects. The choice of model would depend on the sector for which the analysis is being performed. As the project is related to electricity generation, it was categorized as a private utility sector project. In this section, an economic sizing model is developed for the HPFS according to the levelized cost of energy concept. The LCE is defined as [23]:

$$
L C E=\frac{T P V \times C R F}{E_{L O A D}}
$$

where $E_{L O A D}$ is the yearly output in (KWh), TPV and $C R F$ are the total present value of actual cost of all system components and the capital recovery factor, respectively, which can be expressed as follows [23]:

$$
\begin{gathered}
C R F=\frac{i(1+i)^{n}}{(1+i)^{n}-1} \\
T P V=C_{W G}+C_{P V}+C_{F C}+C_{E L E C}+C_{B A T}
\end{gathered}
$$

where $i$ is the annual discount rate, $n$ is the system lifetime in years, $C_{W G}$ the sum of present value of capital and maintenance costs of the WG in system life, $C_{P V}$ the sum of present value of capital and maintenance costs of the PV generator in system life, $C_{F C}$ the sum of present value of capital and maintenance costs of the FC in system life, $C_{E L E C}$ the sum of present value of capital and maintenance costs of the electrolyser in system life and $C_{B A T}$ is the sum of present value of capital and replacement costs of battery bank in system life. The configuration with the lowest LCE is taken as the optimal one from the set of configurations, which guarantee the required LPSP. The annual discount rate is considered as $10 \%$, system lifetime is 20 years and the details of proposed hybrid system components can be found in Table $1[10,18]$. 
Table 1. Details of components

\begin{tabular}{|c|c|}
\hline Wind Generator & \\
\hline Technology & WHISPER 200 \\
\hline Rated Power & $1 \mathrm{KW}$ \\
\hline Cut-in Speed & $1 / 3 \mathrm{~m} / \mathrm{s}$ \\
\hline Rated Speed & $6 / 11 \mathrm{~m} / \mathrm{s}$ \\
\hline Cut-out Speed & $25 \mathrm{~m} / \mathrm{s}$ \\
\hline Capital cost & 3200 US\$ \\
\hline Operation \& Maintenance cost & 100 US\$/year \\
\hline Lifetime & 15 year \\
\hline \multicolumn{2}{|l|}{ PV array } \\
\hline Technology & Polycrystalline \\
\hline Maximum Power & $120 \mathrm{~W}$ \\
\hline Efficiency & $12 \%$ \\
\hline Module unit & $1.07 \mathrm{~m}^{2}$ \\
\hline Short circuit current & $7.74 \mathrm{~A}$ \\
\hline Open circuit voltage & $21 \mathrm{~V}$ \\
\hline Capital cost & 4.84 US\$/Wpeak \\
\hline Lifetime & 20 year \\
\hline \multicolumn{2}{|l|}{ Fuel cell array } \\
\hline Technology & PEMFC \\
\hline PEMFC stack & $100 \mathrm{~W}$ \\
\hline Efficiency & $50 \%$ \\
\hline Operating Temperature & $80^{\circ \mathrm{C}}$ \\
\hline Capital cost & $8 \mathrm{US} \$ / \mathrm{W}$ \\
\hline Replacement cost & $6 \mathrm{US} \$ / \mathrm{W}$ \\
\hline Lifetime & 5000 hour \\
\hline \multicolumn{2}{|l|}{ Electrolyser } \\
\hline Technology & Alkaline \\
\hline Efficiency & $74 \%$ \\
\hline Capital cost & $20 \mathrm{US} \$ / \mathrm{W}$ \\
\hline Lifetime & 20 year \\
\hline \multicolumn{2}{|l|}{ Battery } \\
\hline Technology & Lead-acid \\
\hline Capital cost & $20 \mathrm{US} \$ / \mathrm{KWh}$ \\
\hline Lifetime & 5 year \\
\hline Charging efficiency & $80 \%$ \\
\hline
\end{tabular}

\section{System Optimization}

Different approaches have been reported for optimization cost of generation units such as linear and nonlinear programming, probabilistic approach, dynamic programming, and iterative techniques [16]. Among different iterative techniques, GA and PSO are more attractive.

\subsection{Problem Formulation}

The aim of this study is to achieve a stand-alone hybrid generation system, which should be appropriately designed in terms of economic, reliability, and environmental measures subject to physical and operational constraints/strategies.

\section{a) Objective function}

The function that must be optimized is the system cost. This function is defined as a sum of PV cost $\left(C_{P V}\right)$, battery $\operatorname{cost}\left(C_{B A T}\right)$, electrolyser cost $\left(C_{E L E C}\right)$, and FC cost $\left(C_{F C}\right)$.

$$
C_{\text {SYSTEM }}=C_{W G}+C_{P V}+C_{B A T}+C_{E L E C}+C_{F C}+P F
$$

The cost for each element should be deducted:

$$
\begin{aligned}
C_{i} & =N_{i}^{*}\left[\operatorname{CCost}_{i}+\text { RCost }_{i}^{*} K_{i}+\text { OMCost }_{i}\right] \\
i & =\text { WG, PV, Battery, FC, Electrolyser }
\end{aligned}
$$

Where $N_{i}$ is the number/size of the system component, CCost $_{i}$ is the capital cost, $R$ Cost $_{i}$ is the replacement cost, $K_{i}$ is the number of replacement, and OMCost ${ }_{i}$ is operation and maintenance cost through the system operation. $P F$ is penalty factor that will added to objective function when one or more constrains dose not satisfy. The cost of the system elements can be seen in Table 1.

\section{b) System constraints}

\subsubsection{Power Balance Constraint}

For any period $t$, the total power supply from the hybrid generation system must supply the total demand $P_{L O A D}$ with a certain reliability criterion. This relation can be represented by (29).

$$
P_{W G}+P_{P V}+P_{B A T}+P_{F C}>=P_{L O A D}+P_{E L E C}+P_{S C}
$$

\subsubsection{Bounds of Design Variables}

The proposed hybrid system optimization parameters including the battery capacity $\left(\operatorname{Cap}_{B A T}(K W h)\right)$, number of PV panels $\left(N_{P V}\right)$, and FC power level $\left(P_{F C}(W)\right)$ should be within a certain range:

$$
\begin{gathered}
C a P_{B A T, \text { Min }}<C a p_{B A T}<C a p_{B A T, \text { Max }} \\
N_{W G, \text { Min }}<N_{W G}<N_{W G, \text { Max }} \\
N_{P V, \text { Min }}<N_{P V}<N_{P V, \text { Max }} \\
P_{F C, \text { Min }}<P_{F C}<P_{F C, \text { Max }}
\end{gathered}
$$


Also, as the battery needs certain energy to supply the load in the beginning hours of the next day, battery energy at the end of the day (in normal condition) should be equal or greater than the battery energy at the beginning of the day.

$$
E_{B A T, \text { End }}>=E_{\text {BAT,Start }}
$$

As discussed before, the objective of optimum design of this renewable hybrid generation system is to simultaneously minimize $C_{\text {SYSTEM }}$, as well as maximize system reliability. The design parameters that should be derived include number of WG, number of PV panels, battery capacity and FC power level.

Based on those element costs, the system total cost is defined. The simulation model is run for any combinations of WG, PV surface, battery capacity and FC power level, that are created by PSO and GA. the FC and electrolyser working rate is obtained. After that, these results are used to calculate the total cost of the system, assuming that the system lifetime is 20 years (equal to the PV lifetime).

\subsection{Genetic Algorithm}

GA is a kind of heuristic searching algorithm based on mechanics of natural selection and natural genetics. The global solutions can be found for both linear and nonlinear formulations. The optimal solution searching process is independent of the form of the objective function, and will not be trapped in the rapid descending direction introduced by local minima. In other words, the solution of a complex problem can be started with weak initial estimations and then be corrected in evolutionary process of fitness.

GA evolves into new generations of individuals by using knowledge from previous generations. GA generally includes three fundamental genetic operators of reproduction, crossover and mutation. These operators conduct the chromosomes toward better fitness. In this paper the real code GA is used [17]. More detail of proposed GA is shown in Figure 3.

\subsection{PSO Algorithm}

PSO is a population based stochastic optimization technique developed by Eberhart and Kennedy in 1995 [18]. The PSO algorithm is inspired by social behaviour of bird flocking or fish schooling.

The standard PSO algorithm employs a population of particles. The particles fly through the n-dimensional

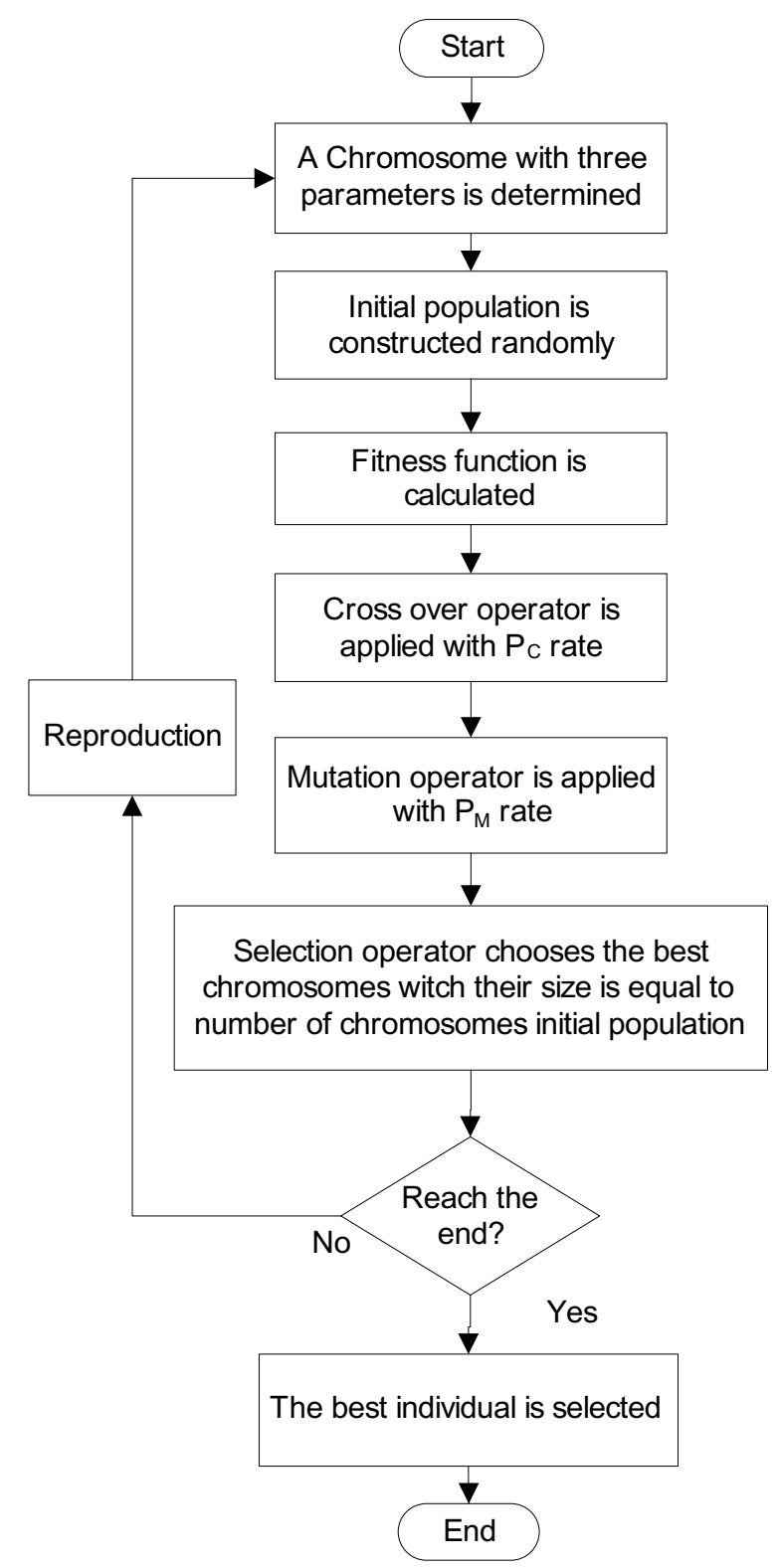

Figure 3. Genetic flow chart.

domain space of the function to be optimized (in this paper, minimization is assumed). The state of each particle is represented by its position $\underline{x}_{i}=\left(x_{i 1}, x_{i 2}, \ldots, x_{i n}\right)$ and velocity $\underline{v}_{i}=\left(v_{i 1}, v_{i 2}, \ldots, v_{i n}\right)$, the states of the particles are updated. The flow chart of the procedure is shown in Figure 4.

During every iteration, each particle is updated by following two "best" values. The first one is the position vector of the best fitness. This particle has achieved so far.

The fitness value $p_{i}=\left(p_{i 1}, p_{i 2}, \ldots, p_{i n}\right)$ is also stored. This position is called pbest. Another "best" position that is tracked by the particle swarm optimizer is the best position, 


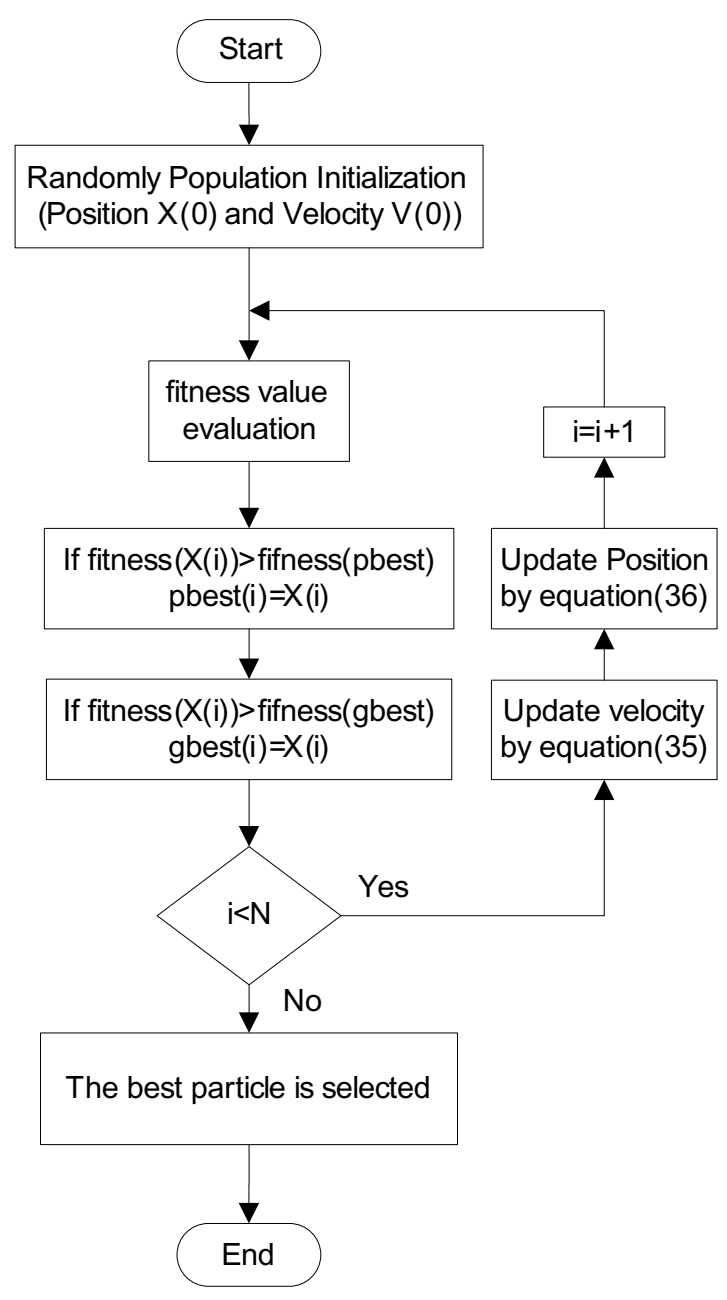

Figure 4. PSO flow chart.

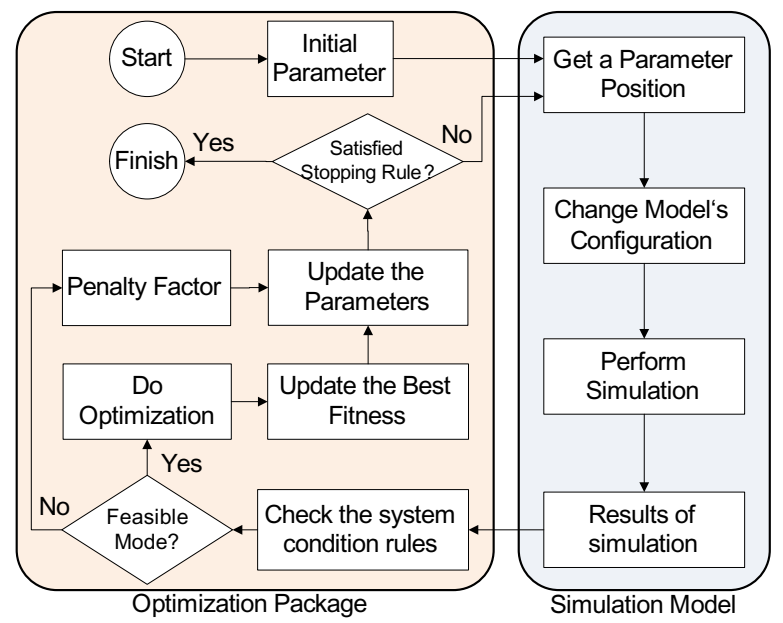

Figure 5. Optimization method on stochastic simulation.

obtained so far, by any particle in the population. This best position is the current global best $p_{g}=\left(p_{g 1}, p_{g^{2}}, \ldots, p_{g n}\right)$ and is called gbest. At each time step, after finding the two best values, the particle updates its velocity and position according to (35) and (36).

$$
\begin{gathered}
v_{i}^{k+1}=w v_{i}^{k}+c_{1} r_{1}\left(\text { pbest }_{i}-x_{i}^{k}\right)+c_{2} r_{2}\left(\text { gbest }_{k}-x_{i}^{k}\right) \\
x_{i}^{k+1}=x_{i}^{k}+v_{i}^{k+1}
\end{gathered}
$$

where $v_{i}^{k+1}$ is the velocity of particle number (i) at the $(k+1)^{t h}$ iteration, $x_{i}^{k}$ is the current particle (solution or position). $r_{1}$ and $r_{2}$ are random numbers between 0 and $1 . C_{1}$ is the self confidence (cognitive) factor; $C_{2}$ is the swarm confidence (social) factor. Usually $C_{1}$ and $C_{2}$ are in the range from 1.5 to $2.5 ; w$ is the inertia factor that takes values downward from 1 to 0 according to the iteration number [19]. When a predetermined termination condition is reached, $p_{g}$ is returned as the optimal value found.

\subsection{GA and PSO Algorithm Parameters}

The PSO results are compared with the GA. Common parameters are assigned to the two algorithms as follows:

- Number of particles/population size:

- $\mathrm{n}=30$.

- The same cost parameters are used for the two algorithms.

For PSO, $C_{1}=1.8, C_{2}=2.2, W$ starts at 1 and decreases until reaching 0 at the end of the run. For the sake of fair comparison of performance between the two algorithms, the stopping criterion is made the same. Mutation rate $=0.8$ and Cross over rate $=0.4$ are used to get the best results of GA. The mating is performed using single point crossover. Figure 5 shows the overall PSO and GA algorithms and how it interplays with the simulation model during optimization.

\section{Results and Discussions}

In this section, several simulations have been made by considering different combinations taking into account, the power of WG, PV and FC and the capacity storage. Technical and economic evaluation of hybrid systems with the proposed method has been studied with Shiraz weather data. According to the available weather data and the large number of variables of the optimization problem, in the most accurate mode, solar radiation, ambient temperature and wind speed can be modeled in the form of hourly curves.

Monthly average of 20 years of Shiraz weather data (Table 2), with sample daily load profiles is used to simulation of proposed system. The estimated hourly load profile 
is shown in Figure 6. The load average in a day is $1(\mathrm{KW})$. It is worth mentioning that for modeling the load annual variation, 365 repetition of curve shown in Figure 6 is used.

Considering the different structure, the system simulation has been done. Then the simulation results are used to optimize the size of the system by GA and PSO. Convergence of the algorithms to obtain the optimum size of the system is shown in Figure 7. It can be seen that the fitness value decreases rapidly in the first 50 generations. During this stage, the GA and PSO concentrate mainly on finding feasible solutions to the problem. Then the value decreases slowly, and they have been converged approximately at the same point after 90 iterations. Consequently the total system cost has been similar in both PSO and GA.

As mentioned before, the optimum size of the system obtained, when the lowest LCE is achieved. In exchange for lowest cost, there will be about $20 \%$ of the excess energy. It should be noted that the reduction in the amount of extra energy in the same system reliability conditions, Lead to

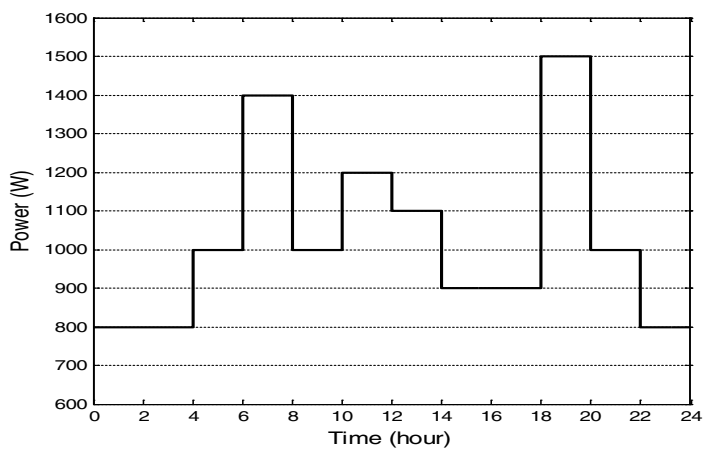

Figure 6. Hourly load profile. increase LCE, thus economically is not affordable. The total cost of system performance in 20 years will be about $59042 \$$. Other values and optimization details are shown in Table 3.

In Figure 8, the LCE is given as a function of excess energy part, according to these results; it is observed that for a minimum value of LCE, an optimal value of excess energy part is exists. For the system configuration considered in this study, this value is about $20 \%$. A reduction in the excess energy part, with the same conditions of the system reliability, increases the LCE. In order to inspection to operation of system according to power management strategy, Figure 9 is presented. In this figure, operation of system in a typical day and normal weather condition on 24 hours term is shown. The parameters are optimum values that are given in table 3. For a start, the FC does not work because the battery SOC is high enough and the solar power is weak, thus the load is supplied by the battery (see Figure 9 (a)). When the battery SOC is lower than the nominal value, the FC is activated and the load is supplied. But the FC is unable to

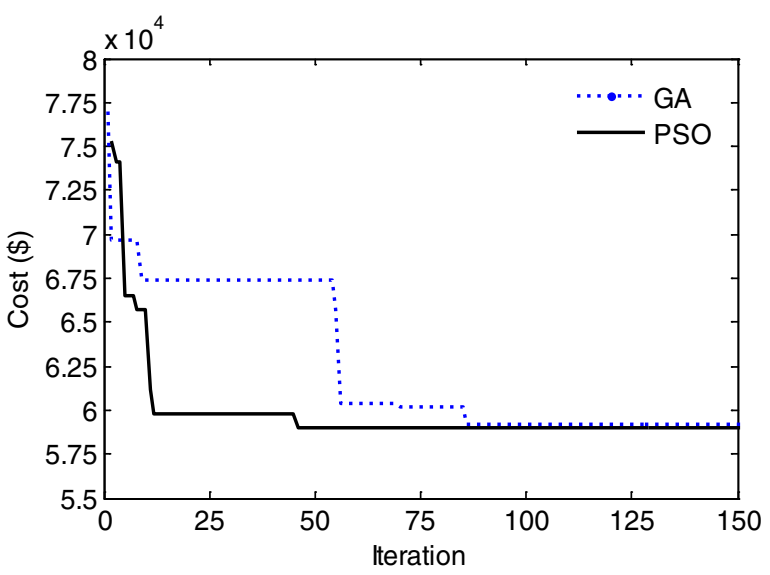

Figure 7. Convergence process of GA and PSO to obtain the optimal solution.

Table 2. Shiraz monthly average of Wind Speed $(\mathrm{m} / \mathrm{s})$, Solar irradiation $\left(\mathrm{Wh} / \mathrm{m}^{2} /\right.$ day $)$, and Ambient temperature $\left({ }^{\circ} \mathrm{C}\right)$

\begin{tabular}{lrrrrrrrrrrrr}
\hline Whether data & JAN & FEB & MAR & APR & MAY & JUN & JUL & AUG & SEP & OCT & NOV & DEC \\
Wind Speed & 5.86 & 6.28 & 6.32 & 5.96 & 6.54 & 6.59 & 7.07 & 6.73 & 6.10 & 5.40 & 5.36 & 5.78 \\
Solar irradiation & 3.27 & 4.27 & 4.94 & 6.00 & 7.03 & 7.49 & 7.02 & 6.72 & 6.02 & 4.91 & 3.64 & 3.04 \\
Ambient temperature & 4.39 & 6.25 & 10.22 & 16.94 & 22.97 & 27.14 & 28.80 & 27.66 & 23.57 & 18.15 & 11.91 & 6.67 \\
\hline
\end{tabular}

Table 3. Optimized values of WG/PV/FC hybrid system

\begin{tabular}{lcclccccc}
\hline Parameter & $\begin{array}{l}\text { Number of } \\
\text { WG }\end{array}$ & $\begin{array}{l}\text { Number of } \\
\text { PV panels }\end{array}$ & $\begin{array}{l}\text { FC } \\
\text { power }\end{array}$ & $\begin{array}{l}\text { Batteries } \\
\text { Capacity }\end{array}$ & LPSP & LCE & EXC & Total cost \\
Optimum value & 3 & 32 & $500 \mathrm{w}$ & $22 \mathrm{KWh}$ & 0 & $0.747 \$ / \mathrm{KW}$ & $20 \%$ & 59042 US\$ \\
\hline
\end{tabular}




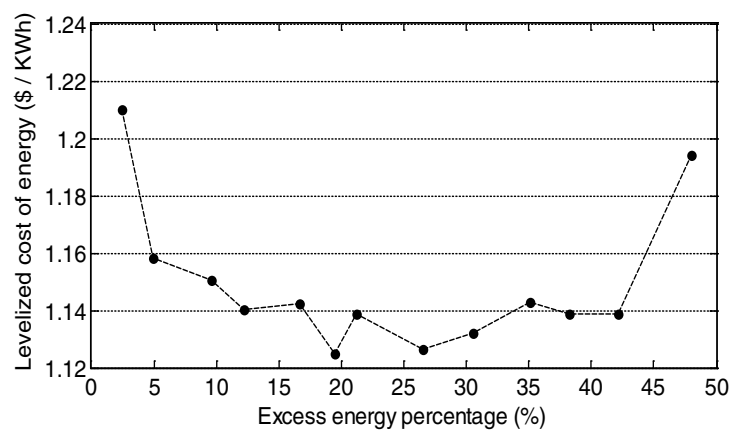

Figure 8. Levelized costs of energy as a function of energy excess part for optimal system configurations.

(a)

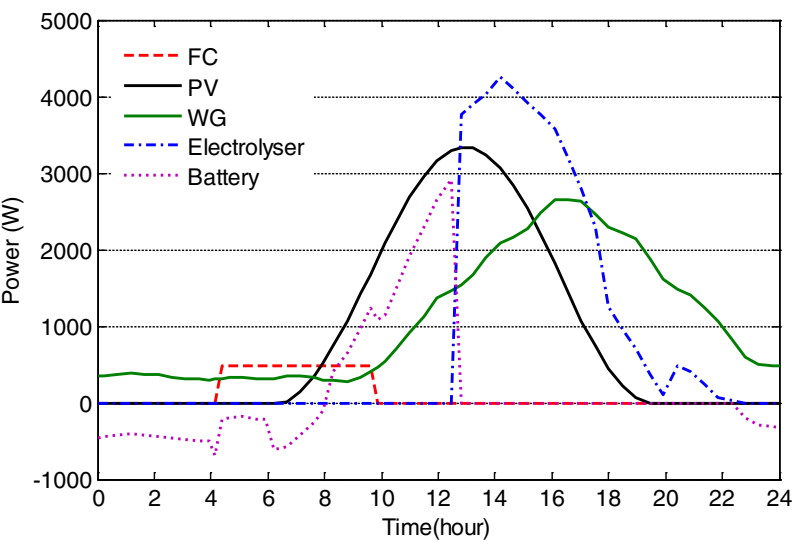

(b)

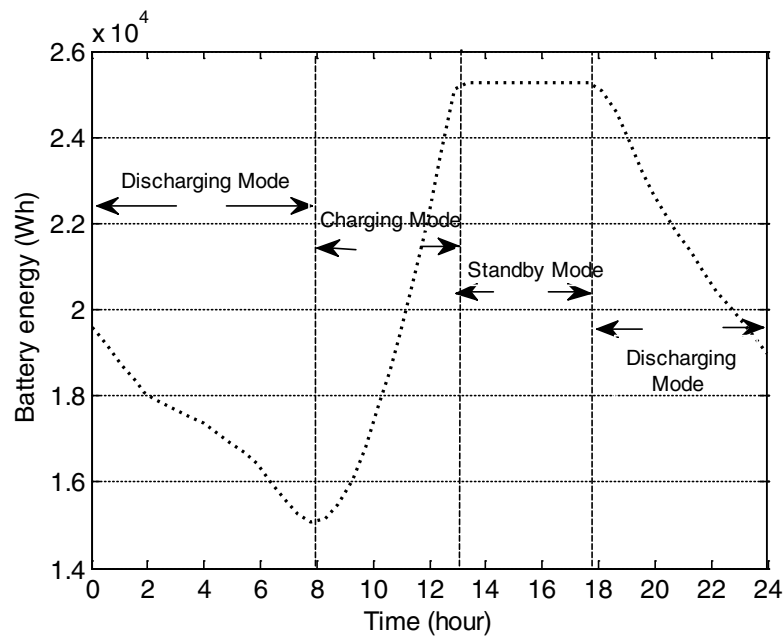

Figure 9. Operation of system: (a) Powers evolutions during 24 hours (b) Energy of battery during 24 hours.

supply the load more than $500 \mathrm{~W}$, thus in spite of low SOC, battery supplies surplus of the load.

As long as the solar power rises during the day, load is mainly supplied by PV and battery is in charging mode. When the battery SOC reaches its maximum allowable value, the battery charging is stopped and the electrolyser is activated. On condition that the FC is working, it supplies the load up to 500 (W); over this value, either PV supplies the additional load or the battery supplies it at the time of the solar radiation does not exist.

During the day, PV charges battery and when battery reaches its nominal SOC, FC is stopped. The battery SOC in different modes of battery operation is shown in Figure 9 (b).

\section{Conclusion}

If the hybrid plants with renewable resources are constructed based on technical and economic studies, they can bring a significant economic benefits. In this paper the optimization of hybrid WG/PV/FC systems with GA and PSO algorithms were performed. Different structures of hybrid systems were obtained by considering LPSP constraints and the one with the lowest Levelized cost of energy is considered as the economical optimal configuration.

To observe the performance of the proposed method and system performance with respect to the designed control strategy, system simulation based on Shiraz weather data was performed. Thus the hybrid system consists of 3 wind turbines, 32 photovoltaic panels, 500 (W) FC, and 22 $(\mathrm{kWh})$ battery capacities was chosen as the most economical structure. The results indicate suitable performance of the proposed method in determining the optimal size of hybrid energy systems.

\section{Acknowledgement}

The authors acknowledge financial support from Young Researchers and Elite Club (YRC), Shiraz Branch.

\section{References}

1. Jalilzadeh S, Kord H et al. (2010). Optimization and technoeconomic analysis of autonomous photovoltaic/fuel cell energy system, ECTI Transactions on Electrical Engineering, Electronics, and Communications, vol 8(2), 118-125.

2. Kord H, and Rouhani A (2009). An integrated hybrid power supply for off-grid applications fed by wind-photovoltaicfuel cell energy systems, 24 $4^{\text {th }}$ International Power System Conference (PSC), Iran.

3. Jalilvand S, Kord H et al. (2009). Design, control and energy management of a hybrid photovoltaic-wind-fuel cell for stand-alone applications, 14th Electrical Power Distribution Conference (EPDC), Iran. 
4. Agbossou K, Kolhe M et al. (2004). Performance of a standalone renewable energy system based on energy storage as hydrogen, IEEE Transactions on Energy Conversion, vol 19(3), 633-640.

5. Bonanno F, Consoli A et al. (1999). Transient analysis of integrated diesel- wind-photovoltaic generation systems, IEEE Transactions on Energy Conversion, vol 14(2).

6. Diaf S, Diaf D et al. (2007). A methodology for optimal sizing of autonomous hybrid PV/wind system, Energy Policy, vol 35(11), 5708-5718.

7. Zhou T, and Francoisn B, (2009). Modeling and control design of hydrogen production process for an active hydrogen/wind hybrid power system, International Journal of Hydrogen Energy, vol 34, 21-30.

8. Ipsakisa D, Voutetakis S et al. (2009). Power management strategies for a stand-alone power system using renewable energy sources and hydrogen storage, International Journal of Hydrogen Energy, 7081-7095.

9. Samaras Z, and Zafeiris D (2007). Optimization of a windpower fuel cell hybrid system in an autonomous electrical network environment, International Journal of Renewable Energy, vol 32, 57-79.

10. Wang C, and Nehrir M H (2008). Power management of a stand-alone wind/photovoltaic/fuel cell energy system, IEEE Trans. on Energy Conversion, vol 23(3), 957-967.

11. Kolokotsa D et al. (2006). Methodology for optimal sizing of stand-alone photovoltaic/wind/generator systems using genetic algorithms, International Journal of Solar Energy, vol 80(9), 1072-1088.

12. Markvard T (2000). Solar Electricity, Chapter IV: Photovoltaic system engineering $2^{\text {nd }}$ Edn., John Willey, USA.

13. Habib M A, Said S et al. (1999). Optimization procedure of a hybrid photovoltaic/wind energy system, Energy, vol 24(11), 919-929.
14. Duffie J A, and Beckman W A (1991). Solar Engineering of Thermal Process, Chapter 10: System thermal calculations $2^{\text {nd }}$ Edn., John Wiley, New York.

15. Chedid R, and Saliba Y (1996). Optimization and control of autonomous renewable energy systems, International Journal of Energy Research, vol 20(7), 609-624.

16. Shakyaa B D, Ayea L et al. (2005). Technical feasibility and financial analysis of hybrid wind-photovoltaic system with hydrogen storage for Cooma, International Journal of Hydrogen Energy, vol 30(1), 9-20.

17. Garcia R S, and Weisser D (2006). A wind/diesel system with hydrogen storage: Joint optimization of design and dispatch, IEEE International Conference on Renewable Energy, vol 31(14), 2296-2320.

18. Lagorse J, Simoẽs M G et al. (2008). Energy cost analysis of a solar-hydrogen hybrid energy system for stand-alone applications, International Journal of Hydrogen Energy, vol 33(12), 2871-2879.

19. Pattipati B, Pattipati K et al. (2008). Automotive Battery Management Systems, IEEE Autotestcon, 581-586.

20. Lu Y, Burnett L et al. (2002). Investigation on wind power potential on Hong Kong islands-an analysis of wind power and wind turbine characteristics, International Journal of Renewable Energy, vol 27(1), 1-12.

21. Bogdan S B, and Salameh Z M (1996). Methodology for optimally sizing the combination of a battery bank and PV array in a wind/PV hybrid system, IEEE Transactions on Energy Conversion, vol 11(2), 367-375.

22. Bin A, Hongxing Y et al. (2003). Computer aided design for PV/Wind hybrid system, International Journal of Renewable Energy, vol 28, 1491-1512.

23. Athanasia A L, and Anastassios D P (2000). The economics of PV standalone residential households: a case study for various European and Mediterranean locations, International Journal of Solar Energy Materials and Solar Cells, vol 62, 411-427. 